\title{
Analysis of Influencing Factors of Financial Asset Allocation of Urban and Rural Residents in Zaozhuang
}

\author{
Sun Benyao \\ Institute of Economics and Management, Zaozhuang University \\ Zaozhuang 277100, China
}

\begin{abstract}
Take Zaozhuang household as research object, based on the micro data from questionnaire survey, using multiple linear regression model, this paper puts forward the structure of urban and rural residents family financial asset allocation of Zaozhuang. Based on empirical analysis of the influencing factors, the results showed that the urban and rural residents of Zaozhuang household financial asset allocation structure has big difference, urban residents have a higher risk of holding financial assets and higher risk of financial assets; rural households investment risk preference is only a significant influencing factor of urban residents' financial asset allocation, and rural residents' financial asset allocation is more sensitive to education level.
\end{abstract}

keywords—family finance; multiple linear regression; internet finance; financial asset

\section{INTRODUCTION}

With the deepening of the reform of the socialist economic system, family has become an important investment subject in the financial market, and family finance has become the third independent research direction after the traditional research fields such as corporate finance and asset pricing theory. Since the reform and opening up 40 years ago, China's per capita disposable income has increased by 22.8 times. Wealth accumulation leads to the increasing investment demand of residents, while the growth rate of financial assets of urban and rural residents in China is much higher than the growth rate of per capita disposable income. In 2015, the total financial assets of households in China were RMB 118,4063, 245.25 times that of RMB 4,828.82 in 1987. In addition, there are prominent contradictions in the dual economic structure between urban and rural areas, unbalanced economic development, and obvious differences in the allocation of financial assets between urban and rural households. Under the background of "Internet +", Internet finance, a new financial model, has been developed qualitatively and has great advantages in improving the efficiency of household finance resource allocation, reducing transaction costs and alleviating information asymmetry. But on the other hand, the variety of Internet financial products also expands the difference of financial asset allocation of urban and rural residents to a certain extent.

As a pilot city for the transformation of resource-exhausted cities in China, Zaozhuang is in a critical period of economic transformation and upgrading, with rapid economic growth, increasing disposable income of urban and rural residents, and increasing financial assets in household assets. Therefore, the research of urban and rural residents of Zaozhuang family status and characteristics of financial assets, analysis of the difference of the financial asset allocation analysis of Internet financial status in the allocation of financial resources and family, to narrow the gap between rich and poor, Zaozhuang region for urban and rural residents family financial asset allocation, improve the efficiency of social resource allocation has important practical significance. In addition, the case study on the allocation of financial resources of urban and rural residents in Zaozhuang has certain reference and guiding significance for the study of similar cities nationwide, thus providing a basis for national macro-control.

The research on household finance in China mainly focuses on the composition and influencing factors of household financial assets. To this end, domestic scholars have done a lot of theoretical and empirical research using macro and micro data. Yi gang (1996) [1]Through the analysis of the financial asset structure since the reform and opening up, it indicates that the direction of financial reform is to improve the financial asset structure, improve the efficiency of resource allocation, and reduce financial risks through management. Li tao (2006) [2]. Based on the analysis of sampling survey data of residents in guangdong province, it is concluded that the proportion of stock assets is affected by social interaction and trust, and the fluctuation of stock market will affect social interaction in turn. Meanwhile, social interaction has a more significant impact on the stock investment behavior of people with low knowledge level. Guo dongqi (2017)[3]Through the research on the financial asset allocation of urban and rural residents in nanjing, it is concluded that the two risky assets with the most disparity are stock and private lending. Zhang yan (2016)[4]Based on Probit and Tobit empirical model, it is concluded that Chinese family financial asset selection has robust preference. However, the preference of choice behavior has structural differences for families with different income levels, regions, ages and educational levels. Gong he (2016)[5]Using questionnaire of xuzhou city residents family is a random sampling of financial assets, and based on factor analysis method, to the situation of urban and rural residents' financial assets allocation of xuzhou region a brief summary, and compares the structure of urban

[Chinese library classification number] F063.4 document code: A 
and rural household financial assets choice, it is concluded that wealth differences is financial asset allocation of the key factors. Ye xuan (2017)[6]Based on the data of China Household Finance Survey 2011 (CHFS) in zhejiang province, multiple regression model analysis shows that age, income and other factors have a prominent impact on the financial asset allocation of urban and rural residents.

\section{DATA SAMPLES AND MODEL SETTINGS}

\section{A. Data acquisition}

Data acquisition form of questionnaire, investigation content CHFS Chinese family financial report information, sampling survey in five area of Zaozhuang city, a total of 900 questionnaires, according to the city's permanent population urbanization rate is $55.47 \%$ for stratified sampling, 400 rural samples, city 500 samples, the actual back 856, 838 valid questionnaires, the effective rate was $97.9 \%$.Of these, 382 were from rural areas and 456 were from cities in February 2018.

\section{B. Variable selection and model setting}

In view of the fact that this paper studies "influencing factors of household financial asset allocation", in order to reflect the asset allocation structure, this paper takes the proportion of financial assets, the proportion of risky financial assets and the proportion of risk-free financial assets as explained variables, among which Internet financial products include network platform financial management, fund, insurance and stocks.According to the classification of household financial assets by wei xiaole (2016), financial assets are divided into risk assets and non-risk assets. Risk assets include stocks, funds, bonds, financial products and private loans; Risk-free assets include cash, bank demand and time deposits, and insurance.
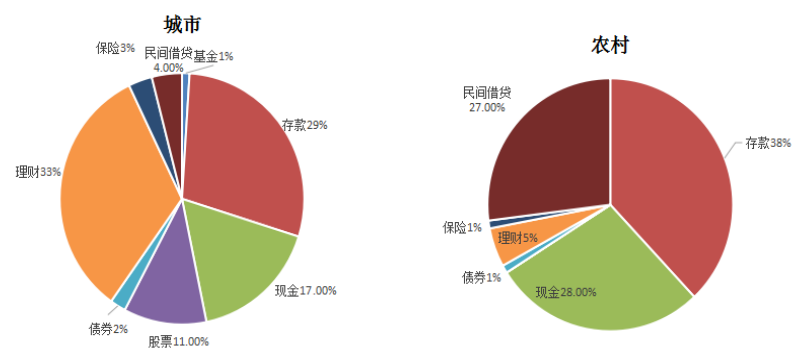

Fig. 1 Ratio of financial asset structure of urban and rural households

Through sorting out relevant theories and literatures, this paper obtains two kinds of factors that affect the allocation of family financial assets: family structure characteristics and family economy and expectation factors. The characteristics of family structure mainly refer to the basic characteristics of head age, education level, gender, investment risk preference and consumption preference. Household economy and expected factors are mainly reflected by income level, economic expectation and housing price expectation, which have a total of 8 variables.

After data collection, the average financial assets of rural residents are 46,500 yuan and that of urban residents is 86,200 yuan. The ratio chart of financial asset structure of urban and rural households is drawn, and the results are shown in figure 1.

TABLE I VARIABLE DESCRIPTION

\begin{tabular}{|c|c|c|}
\hline Symbol & Variable & Instructions \\
\hline$X_{1}$ & age & The age of the head of the household is 2017 - year of birth \\
\hline$X_{2}$ & gender & 1 for men and 2 for women \\
\hline$X_{3}$ & Education level & $\begin{array}{l}\text { 2. Primary school 3. Middle school 4. High school 5. Secondary school/vocational school } \\
\text { 6. Junior college/higher vocational college } 7 \text {. Bachelor's degree } 8 \text {. Master's degree } 9 . \\
\text { The higher the number, the higher the degree }\end{array}$ \\
\hline$X_{4}$ & $\begin{array}{ll}\begin{array}{l}\text { Investment } \\
\text { appetite }\end{array} & \text { risk } \\
\end{array}$ & The smaller the number, the greater the risk preference \\
\hline$X_{5}$ & Consumer preferences & The smaller the number, the more inclined to consume \\
\hline$X_{6}$ & Income level & Family income status \\
\hline$X_{7}$ & Economic forecast & The smaller the number, the more optimistic \\
\hline$X_{8}$ & Prices are expected to & The smaller the number, the higher the probability that the house price will rise \\
\hline
\end{tabular}

As can be seen from the figure, there are differences in the financial asset allocation status of urban and rural households in Zaozhuang city. The financial asset types of urban residents are diverse, while the financial asset structure of rural residents is single. In terms of risky investment, the proportion of risky financial assets of urban residents is $51 \%$, much higher than that of rural residents, which is 34\%. Among risky assets, urban households account for the highest proportion of financial products, while rural households mainly participate in private lending. With the rise of Internet finance, various P2 platforms and third-party payment platforms have become the investment direction of family financial assets, and people are more willing to deposit money into yu 'e bao, WeChat financial wallet and other online financial institutions, which has become an important reason why urban residents' financial assets account for a large proportion. It can be seen that urban families have diversified financial asset portfolios, with higher risk preference and stronger risk management awareness. Rural families pay more attention to the investment of non-risk assets and have weak financial management awareness and risk management awareness. 
OLS linear regression model:

$$
\begin{aligned}
& Y_{1}=a_{0}+a_{1} X_{1}+a_{2} X_{2}+a_{3} X_{3}+a_{4} X_{4}+a_{5} X_{5}+a_{6} X_{6}+a_{7} X_{7}+a_{1} X_{8}+\varepsilon \\
& =Y_{2}+a_{0} \quad a_{1} X_{1} \quad a_{2} X_{2} \quad a_{3} X_{3} \quad a_{4} X_{4} \quad a_{5} X_{5} \quad a_{6} X_{6}+a_{7} X_{7}+a_{1} X_{8}+\varepsilon
\end{aligned}
$$

They are respectively the proportion of risky financial assets and the proportion of risk-free financial assets. $Y_{1}, Y_{2}$ The variable selection is shown in the following table. The characteristics of family structure mainly refer to the basic characteristics of head age, education level, gender, investment risk preference and consumption preference. Household economy and expected factors are mainly reflected by income level, economic expectation and housing price expectation, which have a total of 8 variables.

\section{EMPIRICAL ANALYSIS}

\section{A. Analysis of influencing factors of urban household financial asset allocation}

Linear regression model was used to carry out regression of equation (1), and the results obtained are shown in table 1.

According to the regression results in table 1, among the factors affecting the allocation of risky financial assets of urban residents, the most significant role of investment risk preference is $1 \%$, and there is a significant negative correlation, indicating that the stronger the investment risk preference is, the greater the investment of risky financial assets will be.
Age has a significant positive effect on risky financial assets at the level of $10 \%$, indicating that the higher the age is, the higher the investment proportion of risky financial assets will be.

Consumption preference has a negative impact on risk-free financial assets with a significance level of $5 \%$, indicating that the higher the consumption preference is, the greater the holding of risk-free financial assets will be.

The positive significance level of income level on risky financial assets is $5 \%$, which indicates that urban residents will purchase more risky financial assets with their increased income.

House price expectation has positive impact on risky financial assets, negative impact on risky financial assets and non-risky financial assets, with significance level of $10 \%$ and 5\% respectively. This shows that the expected rise of house price will bring the decline of risky financial asset investment and the rise of risk-free financial asset investment.

TABLE II

INFLUENCING FACTORS OF URBAN HOUSEHOLD FINANCIAL ASSET ALLOCATION

\begin{tabular}{lll}
\hline Variable & Risky financial assets & Risk-free financial assets \\
\hline Age & $987.1^{*}$ & 785.5 \\
\hline Gender & 9832.0 & 59382.2 \\
\hline Education level & 8769.2 & 1873.2 \\
\hline Investment risk appetite & $22674.5^{* * *}$ & 7329.4 \\
\hline Consumer preferences & 3876.1 & $6581.2^{* *}$ \\
\hline Income level & $0.00394^{* *}$ & 0.0750 \\
\hline Economic forecast & 3816.9 & 17924.2 \\
\hline Prices are expected to & $27891.3^{* *}$ & $41781.7^{*}$ \\
\hline
\end{tabular}

\section{B. Analysis of influencing factors of rural family financial asset allocation}

Linear regression model was used to regression equation (2), and the results were shown in table 2.

According to the regression results in table 1, among the factors affecting the allocation of risky financial assets of rural residents, the most significant role of house price expectation is $1 \%$, which has an obvious positive correlation, indicating that the expected decline of house price will bring more investment in non-risky financial assets.

Age has a significant positive effect on risky financial assets at the level of $5 \%$, indicating that the higher the age is, the higher the investment proportion of risky financial assets will be.

Education level is significant and positive at the level of $5 \%$ of risky financial assets, indicating that rural residents with higher education level will hold more risky financial assets.

Consumption preference has negative influence on risk-free financial assets and risk-free financial assets, with a significance level of $5 \%$, indicating that the higher the consumption preference is, the greater the holding of risk-free financial assets and risk-free financial assets will be.

Economic expectations have a negative impact on risk-free financial assets, with a significance level of $5 \%$. The more 
optimistic the economic expectations are, the more the holdings of risk-free financial assets will increase.

The positive significance of income level on risk-free financial assets is $10 \%$, which indicates that rural residents will purchase more risky financial assets with their increased income.

TABLE III INFLUENCING FACTORS OF RURAL HOUSEHOLD FINANCIAL ASSET ALLOCATION

\begin{tabular}{lll}
\hline Variable & Risky financial assets & Risk-free financial assets \\
\hline Age & $276.5^{* *}$ & 284.6 \\
\hline Gender & 2749.8 & 2167.4 \\
\hline Education level & $769.2^{* *}$ & 1374.2 \\
\hline Investment risk appetite & 8476.9 & 1372.6 \\
\hline Consumer preferences & $1896.0^{*}$ & $2381.5^{* *}$ \\
\hline Income level & 0.00394 & $0.0750^{*}$ \\
\hline Economic forecast & 296.2 & $7485.1^{* *}$ \\
\hline Prices are expected to & 239.3 & $428.5^{* * *}$ \\
\hline
\end{tabular}

C. Comparative analysis of influencing factors of financial asset allocation in urban and rural areas

There is a big difference in the allocation structure of financial assets between urban and rural residents in Zaozhuang city. Urban residents hold a higher proportion of risky financial assets, while rural households hold a larger proportion of non-risky financial assets.

The key influencing factors of financial asset allocation in urban and rural areas also have similarities and differences. Investment risk preference is only a significant influencing factor of financial asset allocation of urban residents, so it can be seen that urban residents are more sensitive to risk preference. However, education level is only a significant factor affecting the financial asset allocation of rural residents. This is because the education level of urban residents is relatively high, while the education level of rural residents is generally low, which leads to higher sensitivity of investment structure to education level.

Age, consumption preference, income level and housing price expectation are the common factors influencing the choice of financial assets of urban and rural households. But at the level of significance, there are still differences.

The choice of financial assets of rural residents is more sensitive to the impact of age, with a significance level of $5 \%$, which can be explained by the life cycle theory. The life cycle of human goes through the initial accumulation period of youth, the consumption and saving period of capital in middle age, and the utilization and appreciation period of capital in old age. For rural residents, as they grow older, they will have more wealth and can invest in risky finance. However, in young and middle age, capital is relatively scarce, and most of the wealth is used to accumulate and raise offspring. This is different from the relatively abundant wealth of urban residents, who are under less pressure to accumulate wealth for the next generation.
$(*, 10 \%$ level is significant; $* *, 5 \%$ level is significant; $* * *, 1 \%$ significant $)$

Consumption preference has a negative impact on both rural and urban household financial asset allocation, mainly reflected in the impact on non-risk financial assets, while no significant impact on urban household risk financial assets. This may be because rural households with higher consumption preferences have more incentives to hold more financial assets and thus obtain higher returns for consumption. However, urban residents have higher investment rationality, and the investment of risky financial assets is not significantly affected by consumption preference.

Income of urban households have significant positive influence on financial assets, risk significance level of 5\%, while no significant impact on the rural residents family risk of financial assets, but the risk of financial assets to its influence significance level of $10 \%$, this is because the city residents are more willing to increase incomes for holding a risky financial assets, and rural residents will be increased with the increase of income level, increase the risk of financial assets.

House price expectation has a significant positive impact on both risky financial assets and non-risky financial assets of urban households. However, the impact on the risk financial assets of rural households is not significant, and the significance level of the impact on the non-risk financial assets is $1 \%$. This is because the city is the main area of real estate development, so it will have a greater impact on urban residents. For rural residents, the expected decline in real estate will bring more non-risk financial investment.

\section{POLICY SugGeSTIONS}

According to the research of this paper, income level, risk appetite and housing price expectation have a great impact on the financial asset allocation of urban and rural households in Zaozhuang. Although the allocation of family financial assets in urban areas is diversified, it lacks breadth and depth, while the allocation structure of family financial assets in rural areas is single. Therefore, it is necessary to actively guide urban and rural residents to make reasonable financial investment, 
increase their property income, reduce the risks of family investment, realize the preservation and appreciation of assets, and improve the efficiency of household financial resources allocation.According to the research conclusions, the following Suggestions are put forward.

\section{A. Increase family incomes and balance urban and rural development}

In order to improve the current situation of the lack of the extent and depth of the financial market participation of urban and rural households at risk, the key is to increase the disposable income of residents. The government should reasonably plan the industrial layout, break the dual economic structure, and promote the common development of the five districts and one city. On the other hand, we should increase subsidies to the rural poor and establish and improve the social security system. At the same time, we should strengthen technical training for the poor and cultivate the ability to get rich through hard work so as to reduce the gap between the rich and the poor.

\section{B. Raise the level of education and cultivate financial awareness}

In the era of booming Internet financial market, having certain financial literacy is the basis and premise of participating in financial activities. On the one hand, the government should focus on education, which is the foundation of the country, and improve residents' financial literacy. On the other hand, the government should increase the publicity of financial knowledge and popularize financial education. Financial service Windows will be set up in rural areas and communities to provide residents with financial knowledge training and guidance.

\section{Stabilize the real estate market and introduce real estate} tax.

The fluctuation of the real estate market will affect residents' financial participation, so the government should promptly introduce the real estate tax law, curb the real estate speculation bubble and stabilize the real estate market.

\section{Grasp the "Internet plus" strategy and promote diversification of financial products.}

Urban and rural residents have different demand structures for financial products. Therefore, it is necessary to conduct demand analysis on the market, establish products that meet different demand preferences, and realize the diversification of financial products. However, the double-edged sword of Internet finance also brings some security risks. Internet financial fraud cases keep emerging, disturbing the order of Internet financial market. Therefore, the government should strengthen management, introduce relevant laws and regulations, and regulate the Internet financial market.

\section{CONCLUSION}

With the development of Internet finance, Internet financial products are emerging in an endless stream. It is particularly important to study the allocation structure of family financial assets and the influencing factors to reasonably guide urban and rural residents to make financial investment and regulate the financial environment. The differential analysis of the factors affecting the financial allocation of urban and rural households in Zaozhuang city also plays a guiding role for the local government to improve the financial environment, improve the efficiency of financial asset allocation of urban and rural households, and promote common prosperity.However, due to the limitation of material resources and financial resources, this paper only investigated the number of families to be expanded, and the data model is a more classic multiple linear regression model, in the future research can learn from other advanced models to continue in-depth research.

\section{ACKNOWLEDGMENT}

About the author:

Sun benyao (1990--), female, born in Zaozhuang, shandong province, assistant professor, school of economics and management, Zaozhuang university, master of quantitative economics, school of economics and management, huaqiao university, majoring in econometrics.

Fund projects:

University-level scientific research fund of Zaozhuang university -- youth project "research on the financial problems of urban and rural families in China" (2016QN08)

\section{REFERENCES}

[1] Yi gang. Structural analysis and policy implications of China's financial asset structure [J]. Economic research,1996,12.

[2] Li tao. Social interaction, trust and stock market participation [J]. Economic research,2006,1.

[3] Guo dongqi, lei lei. Analysis of financial knowledge status and countermeasures of urban and rural families in nanjing [J]. Anhui agricultural science,2017.45(17).

[4] Zhang yan. Research on behavioral preference and influencing factors of family financial asset selection [D]. Chongqing: southwest university,2016.

[5] Gong he. Research on differences of influencing factors of financial asset allocation of urban and rural residents in xuzhou [D]. Chengdu: southwest university of finance and economics, 2016

[6] Ye xuan. Research on financial asset allocation status and influencing factors of urban and rural households in zhejiang province [D]. Hangzhou: zhejiang agriculture and forestry university,2017.

[7] Wei xiaole, liu dongge. An empirical study on the factors affecting the financial assets of urban and rural residents in China $[\mathrm{J}]$. National business information, 2016,28 